\title{
Sürtünmeli Delme İşleminde Geometrik Kovan Yüksekliği Denkleminin Deneysel Sonuçlar ile Doğrulanması
}

\author{
Muhammet BAL ${ }^{1}$, Cebeli ÖZEK ${ }^{2}$, Zülküf DEMIR ${ }^{3 *}$ \\ ${ }^{1}$ Makine Eğitimi Anabilim Dalı, Teknik Eğitim Fakültesi, Fırat Üniversite, Elazığ, Türkiye \\ ${ }^{2}$ Makine Mühendisliği Bölümü, Teknoloji Fakültesi, Fırat Üniversitesi, Elazığ, Türkiye \\ ${ }^{2}$ Makine Mühendisliği Bölümü, Mühendislik-Mimarlık Fakültesi, Batman Üniversitesi, Batman, Türkiye \\ ${ }^{1}$ mbal023@gmail.com, ${ }^{2}$ cozek@ firat.edu.tr, ${ }^{3 *}$ zulkuf.demir@ batman.edu.tr
}

\begin{abstract}
Öz: Sürtünmeli delme, kendi ekseni etrafında dönen konik bir takım ile iş parçası arasında, sürtünme sonucu oluşan 1sının etkisiyle, delinen malzemenin yumuşaması ve takımın dalması seklinde uygulanan, geleneksel olmayan bir delik delme yöntemidir. Literatür çalışmalarında, deneysel olarak elde edilmiş kovanların dış kenar eğrilerinin biçimi, geometrik olarak, bir parabol eğrisi şeklinde analiz edilerek kovan yüksekliğinin denklemi, matematiksel olarak elde edilmiştir. Analiz işleminde, parabol eğrisinin denklem katsayısının $(\mathrm{k})$ değer aralığı tespit edilmiştir. Literatür çalışmalarından elde edilmiş ve deneysel olarak ölçülmüş kovan yüksekliği değerlerine göre kovan yüksekliğinin denklemi, delik çapına, malzeme kalınlığına, koniklik açısına, ilerleme hızına ve ayrıca, $\mathrm{k}$ denklem sabitine bağlı olarak elde edilmiş ve tüm sabitleri içeren yeni denklem katsayısı ise mü $(\mu)$ ile ifade edilmiştir. Ayrıca, mü $(\mu)$ katsayısının değeri, malzeme kalınlığına, delik çapına, koniklik açısına ve ilerleme hızına bağlı olarak alabileceği değer aralığı, grafikler yardımıyla gösterilmiştir. Böylece, $\mu$ katsayısının 0 ile 1,21 aralığında olduğu tespit edilmiştir. Bu çalışmada, literatür çalışmalarından elde edilen matematiksel kovan yüksekliği denkleminin doğruluğu, deneysel kovan yüksekliği sonuçlarına bağlı olarak, araştırılmıştır. Literatür çalışmalarına göre matematiksel olarak elde edilmiş kovan yüksekliği denkleminin ve mü $(\mu)$ denklem katsayısının değer aralığının, deneysel kovan yüksekliği değerlerine göre, yaklaşık olarak \%95 oranında, doğru olduğu tespit edilmiştir.
\end{abstract}

Anahtar kelimeler: Sürtünmeli delme, kovan yüksekliği, kovan yüksekliği analizi, mü denklem kat sayısı $(\mu)$.

\section{Confirmation of the Geometric Bushing Height Equation with Experimental Results in Friction Drilling}

Abstract: Friction drilling is an unconventional method of drilling between a conical tool, rotating around its axis, and the workpiece in the form of softening of the drilled material and sink of the tool by the effect of heat, generated by friction. In the literature studies, the shape of the outer edge curves of experimentally obtained bushings is analyzed geometrically, as a parabola curve and the equation of bushing height is obtained mathematically. In the analysis process, the value range of the equation coefficient $(\mathrm{k})$ of the parabola curve was determined. According to experimentally measured bushing height values, obtained from literature studies, the equation of bushing height is obtained, according to hole diameter, material thickness, conical angle, feed rate, and also equation coefficient $\mathrm{k}$, and the new equation coefficient mü $(\mu)$, including all constants, is expressed. Besides, the value of the coefficient $\mathrm{mu}(\mu)$, the range of values it can take depending on the material thickness, hole diameter, conical angle and feed rate are shown with the help of graphs. Therefore, the coefficient $(\mu)$ was found to be between 0 and 1,21. In the present paper, the accuracy of the mathematical bushing height equation, obtained from literature studies, was investigated, depending on experimental bushing height results. According to the literature studies, it was found that the value range of the mathematically obtained bushing height equation and mu $(\mu)$ coefficient were correct according to experimental bushing height values.

Key words: Friction drilling, bushing height, bushing height analysis, mu $(\mu)$ equation constant.

\section{Giriş}

Sürtünmeli delme yönteminin amacı, ince cidarlı malzemelerde, elde edilen kovan yardımıyla bağlantı uzunluğunu arttırmaktır. Sürtünmeli delme işlemi, kendi ekseni etrafında dönen konik bir takım ile iş parçası arasındaki sürtünme sonucu meydana gelen 1sı ile iş parçasının yumuşaması ve takımın dalması biçiminde meydana gelir. Takım, yumuşamış malzemeyi ilerleme hareketi doğrultusunda iterek ve radyal doğrultuda ise merkezkaç etkisi yayarak deliğin alt kısmında bağlantı uzunluğunu arttıran kovanı oluşturur. İşlem sırasında, delinen numuneden boşalan malzemenin bir kısmı yukarıya akar ve pul olarak adlandırılan sızdırmazlık halkasını

\footnotetext{
${ }^{*}$ Sorumlu yazar: fenbilimleri @ firat.edu.tr. Yazarların ORCID Numarasi: ${ }^{1} 0000-0001-7138-8979,{ }^{2} 0000-0001-7603-415 X^{3 *} 0000-0002-$ $0685-3712$
} 
oluştururken ihmal edilebilecek kadar az miktarda malzeme ise konik takımın dönme ve ilerleme hareketlerinin etkisi ile çevreye yayılır [1-4].

Sünek malzemelerin sürtünmeli delinmesinde silindirik, üzerinde çatlakların az olduğu kovan biçimleri elde edilirken, gevrek malzemelerde ise bağlantı uzunluğunu artırmayan, çatlakların yoğun olduğu ve taç yaprağ biçiminde kovanlar elde edilir. İşlem sırasında meydana gelen maksimum 1sı miktarı, yaklaşık olarak iş parçası malzemesinin ergime sıcaklığının 1/3 - 2/3 katı kadardır. Malzeme kalınlığının delik çapına oranı (t/d), oluşan kovanın biçimini ve yüksekliğini etkileyen önemli bir parametredir. Bu oranın artmasıyla kovan oluşumunu sağlayan malzeme miktarı da artar [5-8].

Sürtünmeli delme işlemi genellikle beş aşamada tamamlanır. Birinci aşamada, takım iş parçasına yaklaşır, temas eder ve itme kuvveti maksimuma ulaşır. İkinci aşamada, takımın konik bölgesinin iş parçasına dalmasıyla temas bölgesindeki 1sı miktarı, dönme momentinin etkisiyle hızlı bir şekilde yükselir. Üçüncü aşamada, takımın silindirik bölgesi iş parçasına dalar ve konik takım yumuşamıș malzemeyi aşağıya doğru iter ve kovan oluşmaya başlar. Dördüncü aşamada, takımın omuz kısmı takımın ilerleme hareketinin tersi doğrultuda akan malzemeyi iş parçasının yüzeyine bastırarak sızdırmazlık halkası olarak adlandırılan pulu oluştururken itme kuvveti tekrar yükselir ve maksimum seviyesine ulaşır. Beşinci aşamada ise delik delme işlemi tamamlanır ve konik takım geri çekilir [11].

Kovanın biçimi, takımın ilerleme hareketinin doğrultusunda ilerlemesi ile meydana gelir. İşlemin başlangıcında 1sı etkisiyle yumuşamış ve akıcı hale gelmiş malzeme, takımın ilerleme hareketinin tersi yönünde akar. Yukarı doğrultuda akan malzeme, deliğin giriş kısmında yığılır ve pul şeklini alır. Meydana gelen kovanın yüksekliği, iş parçası kalınlığının yaklaşık 2-3 katı kadar olmaktadır [9-11]. Ayrıca, Sürtünmeli delme işleminde meydana gelen kovanın biçimi bulanık mantık yöntemi ile de incelenebilir [12]. İşlem sırasında sürtünme etkisi ile oluşan 1sı delinen deliğin çevresindeki mikro yapı yeniden kristalleşerek ince taneli ve kararlı bir yapı meydana getirir. Delinen malzemenin mikro yapısı, yüksek sıcaklık, ısıl dönüşüm ve normal deformasyon etkisiyle değişir. İşlem sırasında, ısıdan etkilenmiş bölgede büyük ve uzun tane yapıları arasında bölgesel bir plastik akış meydana gelir ve yeniden kristalleşmiş tabakalar oluşur [13].

Sürtünmeli delme işleminde, seçilen parametrelere bağlı olarak meydana gelen moment, eksenel kuvvet ve 1S1 transferi sayısal olarak sonlu elemanlar metodu, analitik model ve 3D yazılımlar yardımıyla da analize edilebilir. Modelleme yöntemleri ile iș milinin devir sayısının artması ile meydana gelen sıcaklık değerlerinin deneysel çalışmalarda ölçülen değerler ile benzerlik gösterebilir [8, 12, 14]. İşlem sırasında sürtünme kaynaklı oluşan sıcaklığın miktarı işlemi, özellikle kovanın geometrik boyutlarını ve böylece işlemin kalitesini etkileyen en önemli parametredir. Ayrıca, işlem sırasında meydana gelen kovanın geometrik boyutları: çeper kalınlığı ve yüksekliği, malzeme kalınlığının artması ile düzenli bir şekilde artar [15].

Sürtünmeli delme işlemi ile ilgili literatürde yapılan deneysel çalışmalardan elde edilmiş kovanların dış çeper eğrileri geometrik olarak bir parabol şeklinde analize edilebilir. Sürtünmeli delinen malzemeden boşalan toplam malzemenin hacmi, kovanı ve pulu oluşturan malzemelerin toplam hacmine eşitlenerek kovan yüksekliğini, malzeme kalınlığına, delik çapına, koniklik açısına ve ilerleme hızına bağlı olarak, matematiksel bir şekilde, deneysel çalışma yapılmadan hesaplanabilir. Ayrıca, kovan yüksekliği denklemindeki mü $(\mu)$, denklem katsayısı 0 ile 1,21 aralığında değerler alır.

Sürtünmeli delme işleminin temel amacı ince cidarlı malzemelerde, elde edilen kovan yardımıyla bağlantı uzunluğunu ve mukavemetini arttırmaktır. Bu amaçla, işlemde oluşan kovanın, çeper kalınlığı ve yüksekliği gibi geometrik boyutları işlemin temel amacını oluşturur. Kovanın geometrik boyutları üzerinde en etkili olan parametreler: delik çapı, numune malzemenin çeper kalınlığı, takımın koniklik açısı ve seçilen ilerleme hızıdır. Literatür çalışmalarında, bu parametrelere bağlı olarak, deneysel herhangi bir uygulama yapmadan, seçilen herhangi bir malzemenin sürtünmeli delme işleminde elde edilebilecek kovanın yüksekliği yaklaşık olarak hesaplanabilir [16]. Bu çalışmada ise deneysel olarak elde edilmiş ve yüksekliği ölçülmüş kovanların boyutları, literatür çalışmalarından elde edilmiş denkleme uygunluğu analiz edilmiştir. Ayrıca, literatür çalışmalarından elde edilmiş kovan yüksekliği denkleminin, bu çalışmadan elde edilmiş kovan yüksekliği değerlerine göre, doğruluğu incelenmiştir.

\section{Deneysel Çalışma}

Yapılan çalıșmada 2, 4, 6, 8 ve $10 \mathrm{~mm}$ kalınlıklarında, 70x500 mm boyutlarında hazırlanmış A7075 ile St37 levhalar 5,10,15 ve $20 \mathrm{~mm}$ çaplarında, sırasıyla, HSS ve WC konik takımlar ile 1120 dev/dak devir sayısında ve $25 \mathrm{~mm} / \mathrm{dev}$ ilerleme hızında sürtünmeli delinmiştir. Deneyler, Şekil $1 \mathrm{a}, \mathrm{b}$ ve c'de gösterildiği gibi Fırat Üniversitesi Teknoloji Fakültesi Makine Mühendisliği CNC atölyesinde, TAKSAN APU П 400 tipi konvansiyonel freze tezgâhında gerçekleştirilmiştir. Deney numuneleri, bağlama kalıbı (Şekil 1.b) yardımıyla tezgâha 
bağlanmıştır. Şekil 2'de ise deneysel çalışmada kullanılan hem HSS hem de WC takımların geometrik boyutları gösterilmiştir.

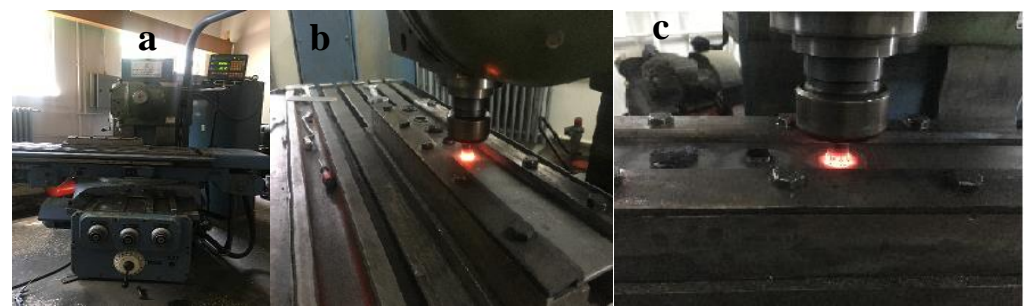

Şekil 1. a) Freze tezgâhı, b) bağlama kalıbı, c) deney seti.

İşlemde kullanılan, Şekil 2 a'd geometrik boyutları ve Şekil 2 b'de ise fotoğrafları gösterilmiş olan konik takımların geometrik boyutları Tablo 1'de belirtilmiş̧ir. Bu geometrik boyutlar: Ød delinecek delik çapı veya takımın delinecek delik çapına eşit olan boyutudur. ØD konik takımın tezgaha bağlanmasını sağlayan sap kısmının çapıdır. Bu çapın değeri standart pens çaplarına uygun olması istenir. Böylece, konik takımla pensler yardımıyla tezgaha bağlanabilirler. ØDI çapı takımın omuz bölgesinin çapıdır. Bu boyutun değeri takımın hem delik çapından (Ød) hem de sapın çapından (ØD) daha büyük seçilir. Böylece, işlem sırasında ergiyerek yumuşamış, fakat delinen levhanın üst yüzeyine doğru akan malzemeyi, işlem sonunda, levhanın yüzeyine bastırır ve pul olarak adlandırılan sızdırmazlık halkasını oluşturur. T, konik takımın omuz bölgesinin kalınlı̆̆ıdır. Bu kalınlık, takımın işlem sırasında maruz kaldığı gerilmeleri taşıyabilecek boyutlarda olması tercih edilir. Özellikle çentik etkisi de göz önünde bulundurulur. L, konik takımın sap bölgesinin uzunluğudur. Bu uzunluk penslerin ölçülerine göre ayarlanir.
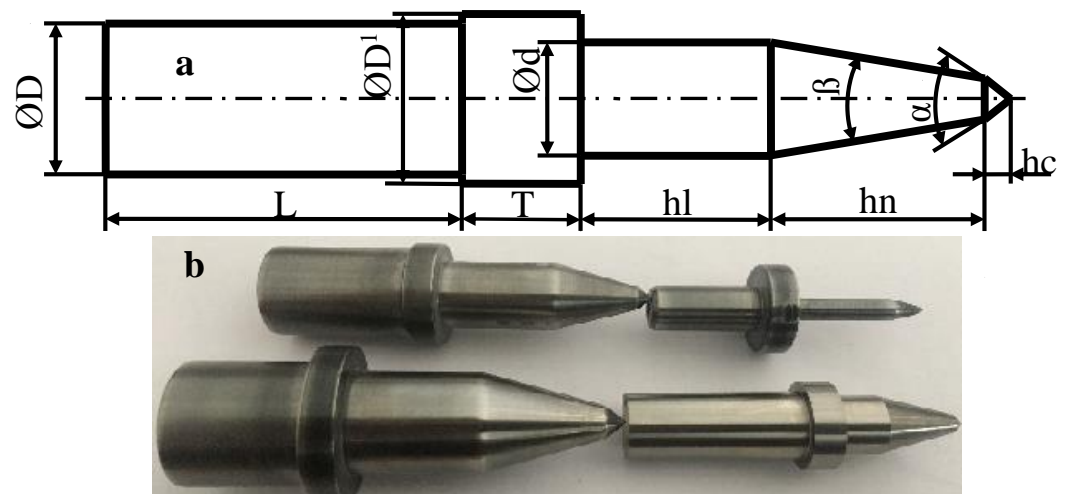

Şekil 2. Sürtünmeli delme işleminde kullanılan a) takımların geometrik boyutları, b) takımların fotoğrafları.

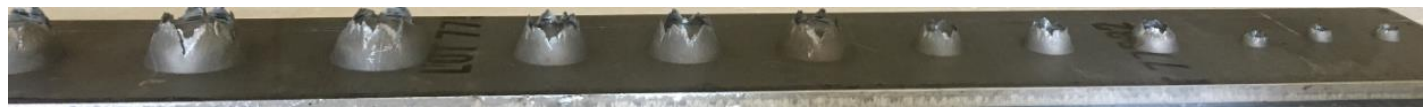

Şekil 3. Sürtünmeli delme işlemi sonucunda elde edilen numuneler.

Deneysel çalışma sırasında oluşan ısının bir sonraki deliğe etkisini önlemek amacıyla Şekil 3'de gösterildiği gibi art arda delinmiş delikler birbirlerinden uzakta sabit mesafelerde delinmiştir. Ayrıca, her bir delik için farklı bir takım kullanıldığından takım değiştirme sürecinde ısınmış iş parçası soğumuştur. Delme işlemi $2 \mathrm{~mm}$ kalınlıktaki deney numunesi ile başlanmış, her numuneye dört farklı çapta üçer adet olmak üzere toplam on iki adet delik delinmiștir. Delme işlemi sırasıyla 2, 4, 6, 8 ve $10 \mathrm{~mm}$ kalınlıklardaki deney numuneleriyle devam edilmiştir. Deney numuneleri, özel hazırlanmış bağlama aparatı yardımıyla, rijit şekilde sabitlendikten sonra konik takımlar değiştirilerek deneyler yapılmıştır. Şekil 4 'te deney numunelerinden elde edilmiş kovanların geometrik boyutlarından biri olan yüksekliğinin boyut sınırları gösterilmiş̧tir. 

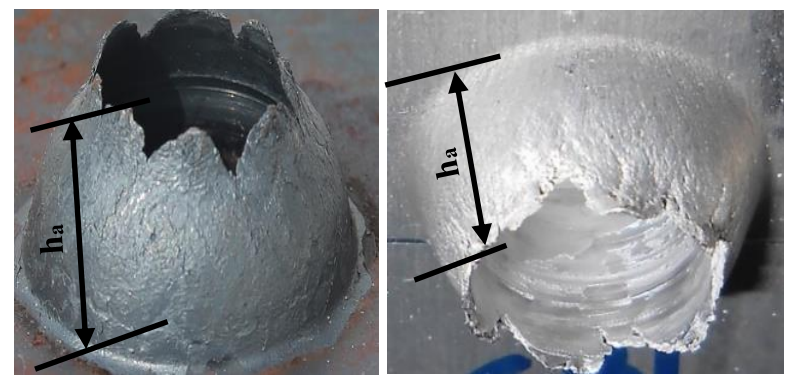

Şekil 4. Deney numunelerinde kovan yüksekliği gösterilişi.

Tablo 1. Konik takımların geometrik boyutları.

\begin{tabular}{|c|c|c|c|c|c|c|c|c|}
\hline $\begin{array}{c}\text { Takim } \\
\text { No: }\end{array}$ & $\begin{array}{c}\boldsymbol{\varnothing d} \\
\mathbf{m m}\end{array}$ & $\begin{array}{c}\boldsymbol{\varnothing D} \\
\mathbf{m m}\end{array}$ & $\begin{array}{c}\boldsymbol{\varnothing} \mathbf{\mathbf { I }} \\
\mathbf{m m}\end{array}$ & $\begin{array}{c}\mathbf{T} \\
\mathbf{m m}\end{array}$ & $\begin{array}{c}\mathbf{L} \\
\mathbf{m m}\end{array}$ & $\begin{array}{c}\boldsymbol{\beta} \\
\mathbf{(}^{\circ}\end{array}$ & $\begin{array}{c}\boldsymbol{\alpha} \\
\mathbf{(}^{\circ}\end{array}$ & $\begin{array}{c}\mathbf{h l} \\
\mathbf{m m}\end{array}$ \\
\hline 1 & 5 & 10 & 18 & 5 & 25 & 36 & 90 & 24 \\
\hline 2 & 10 & 15 & 12 & 5 & 25 & 36 & 90 & 24 \\
\hline 3 & 15 & 20 & 18 & 5 & 25 & 36 & 90 & 24 \\
\hline 4 & 20 & 25 & 24 & 5 & 25 & 36 & 90 & 24 \\
\hline 5 & 5 & 10 & 18 & 5 & 25 & 36 & 90 & 24 \\
\hline 6 & 10 & 15 & 12 & 5 & 25 & 36 & 90 & 24 \\
\hline 7 & 15 & 20 & 18 & 5 & 25 & 36 & 90 & 24 \\
\hline 8 & 20 & 25 & 24 & 5 & 25 & 36 & 90 & 24 \\
\hline 9 & 5 & 10 & 18 & 5 & 25 & 36 & 90 & 24 \\
\hline 10 & 10 & 15 & 12 & 5 & 25 & 36 & 90 & 24 \\
\hline 11 & 15 & 20 & 18 & 5 & 25 & 36 & 90 & 24 \\
\hline 12 & 20 & 25 & 24 & 5 & 25 & 36 & 90 & 24 \\
\hline 13 & 5 & 10 & 18 & 5 & 25 & 36 & 90 & 24 \\
\hline 14 & 10 & 15 & 12 & 5 & 25 & 36 & 90 & 24 \\
\hline 15 & 15 & 20 & 18 & 5 & 25 & 36 & 90 & 24 \\
\hline 16 & 20 & 25 & 24 & 5 & 25 & 36 & 90 & 24 \\
\hline 17 & 5 & 10 & 18 & 5 & 25 & 36 & 90 & 24 \\
\hline 18 & 10 & 15 & 12 & 5 & 25 & 36 & 90 & 24 \\
\hline 19 & 15 & 20 & 18 & 5 & 25 & 36 & 90 & 24 \\
\hline 20 & 20 & 25 & 24 & 5 & 25 & 36 & 90 & 24 \\
\hline
\end{tabular}

\section{Kovan Biçiminin Geometrik Analizi ve Kovan Yüksekliği}

\subsection{Kovan Biçiminin Geometrik Analizi}

Sürtünmeli delme işleminde elde edilen kovanın geometrik boyutları yüksekliği ve çeper kalınlığıdır. Şekil 4' de kovan yüksekliğinin boyut sınırları gösterilmiştir. Sürtünmeli delme işleminde, kovanın oluşumu, konik takımın ilerleme doğrultusunun tersi doğrultuda hareket etmesi ile tamamlanır. İşlemin başlangıcında takım iş parçasına temas eder etmez sürtünme 1sısı hızlı bir şekilde yükselir. Böylece, delinen malzeme 1sı etkisiyle yumuşayarak üst tarafa doğru akar ve pul olarak adlandırılan sızdırmazlık halkasını oluşturur. Konik takımın ucu, yaklaşık olarak iş parçası çeper kalınlığının yarısı derinliğe ulaşıncaya kadar pul oluşumu, takımın ucu iş parçası çeper kalınlığının yaklaşık olarak yarısı derinliği geçinceye kadar devam eder ve daha sonra kovan oluşmaya başlar. Takımın ucu yaklaşık olarak iş parçasının kalınlığının yarısına ulaştığı konumdan itibaren kovan oluşumu da başlar. Şekil 5'de kovan oluşumu aşamaları belirtildiği gibi takımın omuz kısmı yukarıya akan ve pulu oluşturan malzemeyi delinen malzeme yüzeyine bastırarak kovan oluşumu tamamlanır ve takım geri çekilir. 

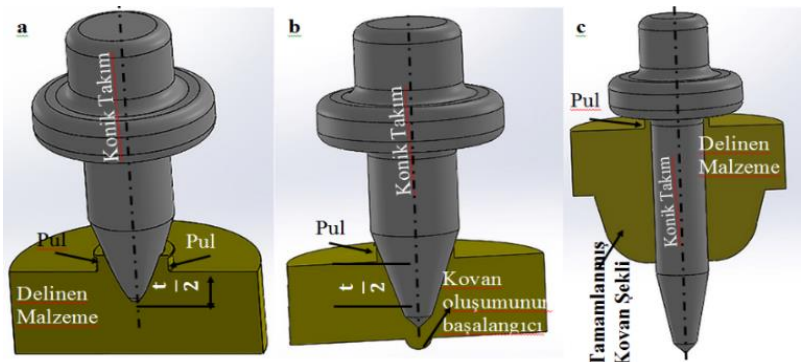

Şekil 5. Kovan oluşumunun adımları, a) Pul Oluşumu, b) Kovan Şeklinin Oluşumu, c) Kovan Şeklinin Tamamlanmasi [16].

\subsection{Sürtünmeli Delme İşleminde Meydana Gelen Kovanın Hacmi}

Sürtünmeli delme işleminde 1s1 etkisiyle yumuşayarak boşalan toplam malzemenin hacmi $V_{\mathrm{E}}$ olarak alınmıştır. İşlem sırasında çevreye yayılan malzemenin hacmi ihmal edildiği kabul edilirse boşalan toplam malzeme hacmi $\left(\mathrm{V}_{\mathrm{E}}\right)$ pulun $\left(\mathrm{V}_{\mathrm{F}}\right)$ ve kovanın $\left(\mathrm{V}_{\mathrm{B}}\right)$ hacimlerinin toplamının eșit olduğu Şekil 6'da görülmektedir [16].

$V E=V F+V B$
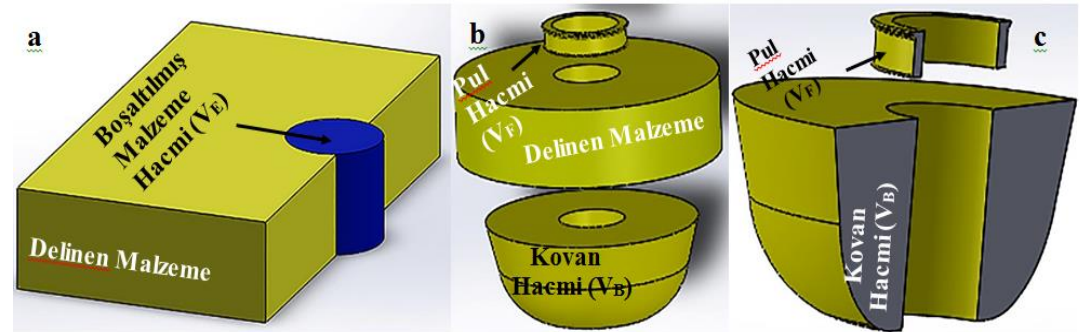

Şekil 6. Boşaltılan malzemenin hacmi, a) boşaltılan malzeme, b) pul ve kovan, c) pul ve kovanın kesit görünüşü [16].
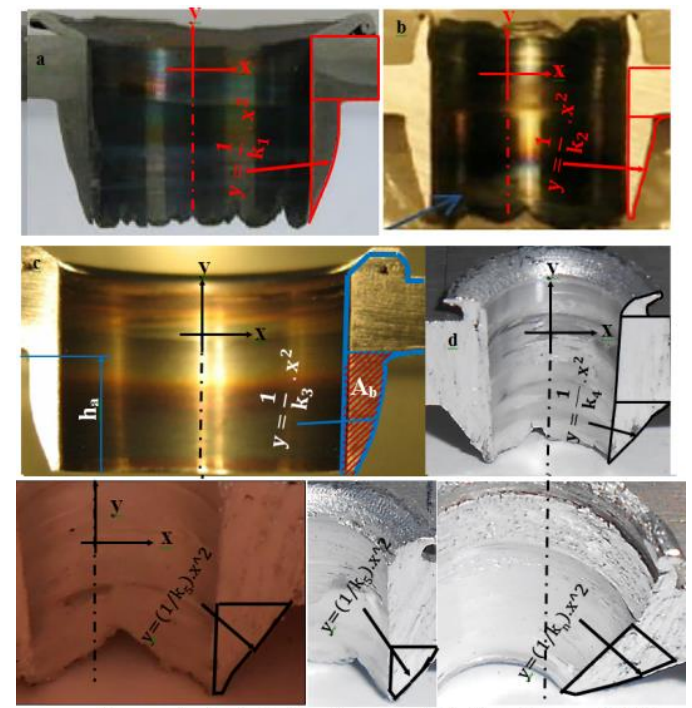

Şekil 7. Farklı Deneysel Çalışmalarda Elde Edilen Kovan Biçimlerinin Kesit Görünüşleri.

Sürtünmeli delme yöntemiyle elde edilmiş kovanların kesit biçimleri Şekil 7'de gösterilmiş̧ir. Şekilde de görüldüğü gibi kovanın dış çeper eğrisi bir parabol eğrisine benzemektedir. 
Kovan biçimi, özellikle kovanın yüksekliği ve çeper kalınlığı gibi geometrik boyutları, bağlantı uzunluğunu ve mukavemetini artıran önemli değerlerdir. Kovan biçimlerinin diş eğrisi geometrik olarak parabol eğrisine benzer. Bu benzerlik yardımı ile kovanın yüksekliği malzemeden boşalan toplam malzemenin ve kovanın hacimlerine bağlı olarak hesaplanabilir. Parabol eğrisinin eğimi farklılık gösterir. Eğrinin eğimindeki bu farklılık (k) sabiti ile belirtilirse kovanın biçimini oluşturan eğrinin eğimi delik çapına, malzeme kalınlığına, devir sayısına, ilerleme hızına, konik takımın ve delinen malzemenin özelliklerine bağlı olarak farklılık gösterir. Eğrinin eğimindeki bu farklılığa bağlı olarak kovanın yüksekliği değişir.
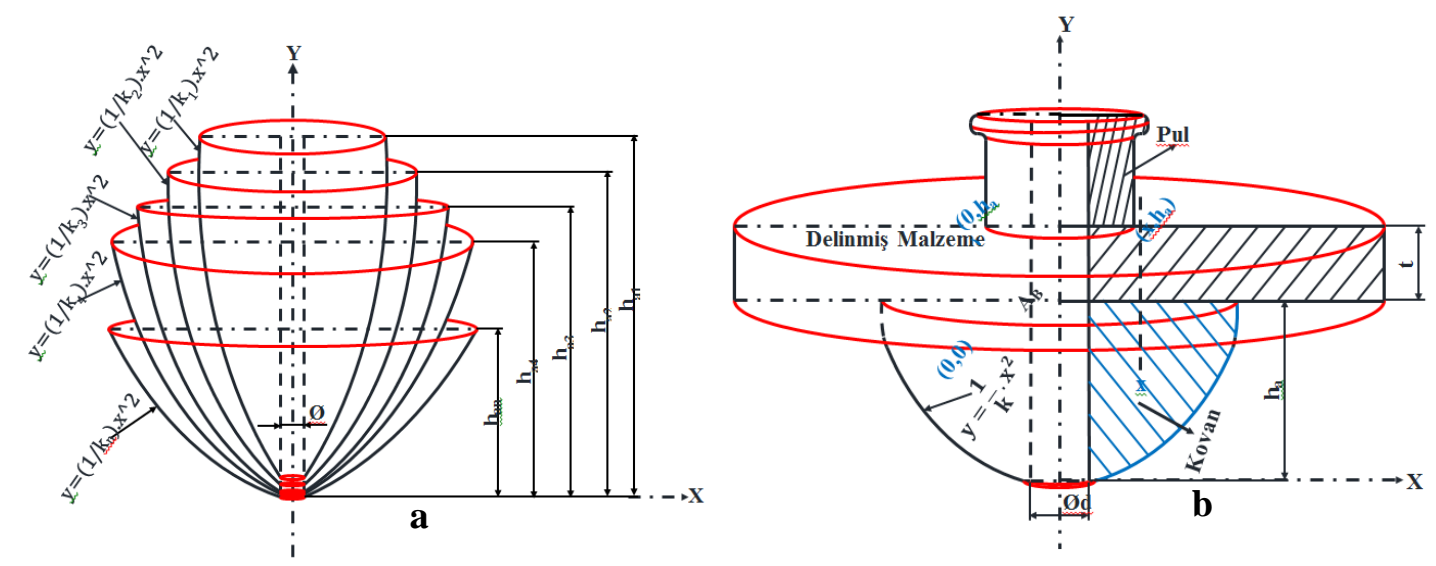

Şekil 8. a) Kovan dış eğrisinin biçimi, b) sürtünmeli delmede kovan denkleminin eğri biçiminde elde edilmesi [16].

Parabol'un eğri denklemi, denklem 2'de gösterilmiştir. Bu eğrinin eğimi kovan yüksekliğini doğrudan etkileyen bir parametredir. Kovanın dış çeper eğrisinin eğimi kovan yüksekliğini etkileyen parametre olduğunu geometrik olarak Şekil 8a ve Şekil 8b’de gösterilmiştir [16].

$y=\frac{1}{k} x^{2}$

Kovan yüksekliğinin denklemi, sürtünmeli delinen delik çapına, malzemenin kalınlığına, takımın koniklik açısına, ilerleme hızına ve $\mu$ kat sayısına bağlı denklem 3 'te gösterildiği gibi ifade edilebilir [16].

$h_{a}=\frac{d}{4 . \mu}+\sqrt{\left[\frac{\cdot d^{2}}{16 . \mu^{2}}-\frac{t^{3} \cdot \tan ^{2}(\beta)}{12 . d . \mu}+\frac{500 \cdot t . f}{d . \mu^{2}}\right.}$

Denklem 3'teki $\mu$ katsayısı delik çapına, malzeme kalınlığına bağlı olarak Şekil 9a da gösterilmiştir. Ayrıca $\mu$ katsayısının ilerleme hızına ve takımın koniklik açısına bağlı olarak sırasıyla Şekil 9b ve c deki grafiklerden seçilebilir. Ancak kovan yüksekliği üzerindeki en etkili parametreler, sırasıyla, delik çapı (konik takımın çapı (d)) ve sürtünmeli delinen malzeme (t) kalınlığıdır. Bu nedenle $\mu$ katsayısı sadece delik çapına ve malzeme kalınlığına bağlı olarak seçilebilir. Belirlenen işlem parametrelerine göre deneysel çalışmadan önce elde edilebilecek kovan yüksekliği $\left(h_{a}\right)$ denklem 3 yardımıyla teorik olarak, kabul edilebilir bir hata oranı ile hesaplanabilir. Bu çalışmamızda seçtiğimiz parametrelerin değerleri denklem 3 'te yazılarak hesaplanan kovan yüksekliği değerleri deneysel olarak ölçülen kovan yüksekliği sonuçları ile karşılaştırılmıştır. 
a Delik Çapı \& Denklem Sabiti \& Malzeme Kalınlığı

- - Delik Çapı $(\mathrm{d})$
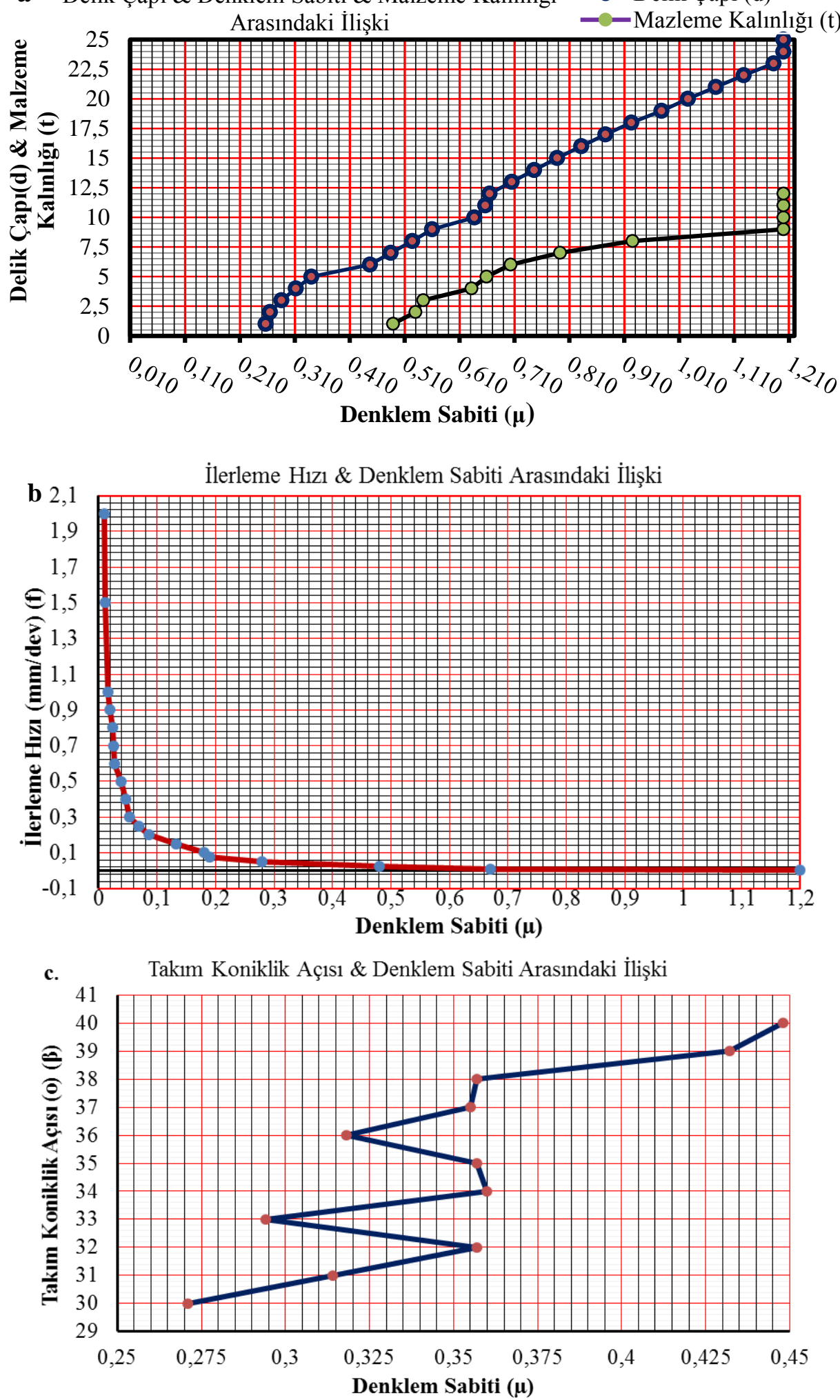

Şekil 9. Denklem 3 'teki ( $\mu$ ) sabiti için a) delik çapına (d) malzeme kalınlığına (t), b) ilerleme hızına (f), c) koniklik açısına $(\beta)$ bağlı olarak seçilebilecek değerler [16].

\section{3. $\boldsymbol{\mu}$ Denklem Katsayısının Delik Çapına Ve Malzeme Kalınlığına Göre Analizi}




\subsection{1 $\mu$ Denklem Katsayısının Al 7075 ve St37 Delik Çapına Göre Analizi}

$\mu$ denklem katsayısının değeri, delik çapına, malzeme kalınlığına, ilerleme hızına ve koniklik açısına göre Şekil 9 a, b ve c'deki grafiklerden, sırasıyla, delik çapı ile malzeme kalınlığına, ilerleme hızına ve takım koniklik açısına bağlı olarak seçilebilir[16].

Yapılan çalışmaya göre $\mu$ denklem katsayısının delik çapına ve malzeme kalınlığına göre alabileceği değerlerin sınırları, ilerleme hızına ve koniklik açısına göre alacağı değerleri de kapsamaktadır. Bu nedenle $\mu$ denklem değerinin teorik olarak alabileceği değerleri delik çapına ve malzeme kalınlığına göre analiz edilmiştir.

Şekil 10'da $\mu$ denklem katsayısının Al7075 ve St37 delik çapının kovan yüksekliği göre etkisi gösterilmiştir. $\mathrm{Bu}$ grafikte kovan yüksekliğini belirlemek için literatürdeki çalışmadan elde edilen Şekil 9'daki grafikten seçilmiştir. Seçilen bu değerler delik çapları göz önüne alınarak belirlenmiştir.

Şekil 10'da denklem 3 yardımıyla hesaplanan kovan yüksekliği değerleri, delik çapına göre hem A7075 alüminyum alaşımı hem de St37 çelik malzemelerinin sürtünmeli delinmesinde elde edilen kovan yükseklikleri karşılaştırılmıştır. $\mu$ değeri, delik çapına bağlı olarak Şekil 8a'daki grafikten seçilmiştir. Seçilen $\mu$ değerlerine göre hesaplanan ve deneysel çalışmada ölçülen kovan yüksekliği değerleri karşılaştırılmıştır. Şekil 10'da 1-20 arası verilen değerler deney sırasıdır. Şekil 10'daki grafiğin üzerindeki noktalar, malzeme kalınlığı değerleri 2-10 mm aralığında ve delik çapının ise $\varnothing 5 \mathrm{~mm}$ - Ø20 mm aralığında değişmesi ile kovan yüksekliği denkleminin katsayısı

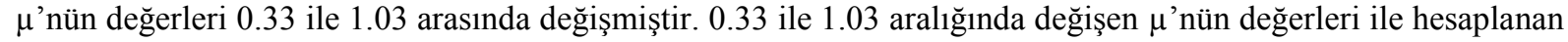
kovan yüksekliği değerleri ile hem A7075 alaşımının hem de St37 çelik levhaların sürtünmeli delinmesinde ölçülen kovan yüksekliği değerleri arasında uyumlu bir değişimin olduğu tespit edilmiştir. St37 çelik malzemenin sürtünmeli delinmesinde elde edilen kovanların yüksekliği değerleri hem teorik olarak hesaplanan hem de A7075 alaşımın sürtünmeli delinmesinde ölçülen kovan yüksekliği değerlerinden daha yüksek olmuştur. En küçük kovan yüksekliği değerleri $2 \mathrm{~mm}$ malzeme kalınlığında ve $\varnothing 5 \mathrm{~mm}$ delik çapında elde edilirken, en büyük değerler ise 10 mm malzeme kalınlığında ve $20 \mathrm{~mm}$ delik çapında elde edilmiştir. Teorik olarak hesaplanan ve deneysel olarak ölçülen kovan yüksekliği değerlerinin değişim grafikleri benzerlik gösterdiği, birbiriyle uyumlu bir değişim göstermiştir. Hem A7075 alaşımının hem de St37 çelik levhaların sürtünmeli delinmesinde elde edilen kovan yüksekliği değerlerinin teorik olarak hesaplanan değerler ile en iyi uyum gösterdiği noktalar 2, 6 ve 10 sira numaralı deneyler olmuştur. Diğer bir ifade ile $2 \mathrm{~mm}$ malzeme kalınlığı, Ø5 mm delik çapı, $4 \mathrm{~mm}$ malzeme kalınlığı, Ø10 mm delik çapında ve 6 mm malzeme kalınlığı, Ø10 mm delik çapında hem teorik hem de deneysel kovan yüksekliği değerlerinin uyum göstermiştir.

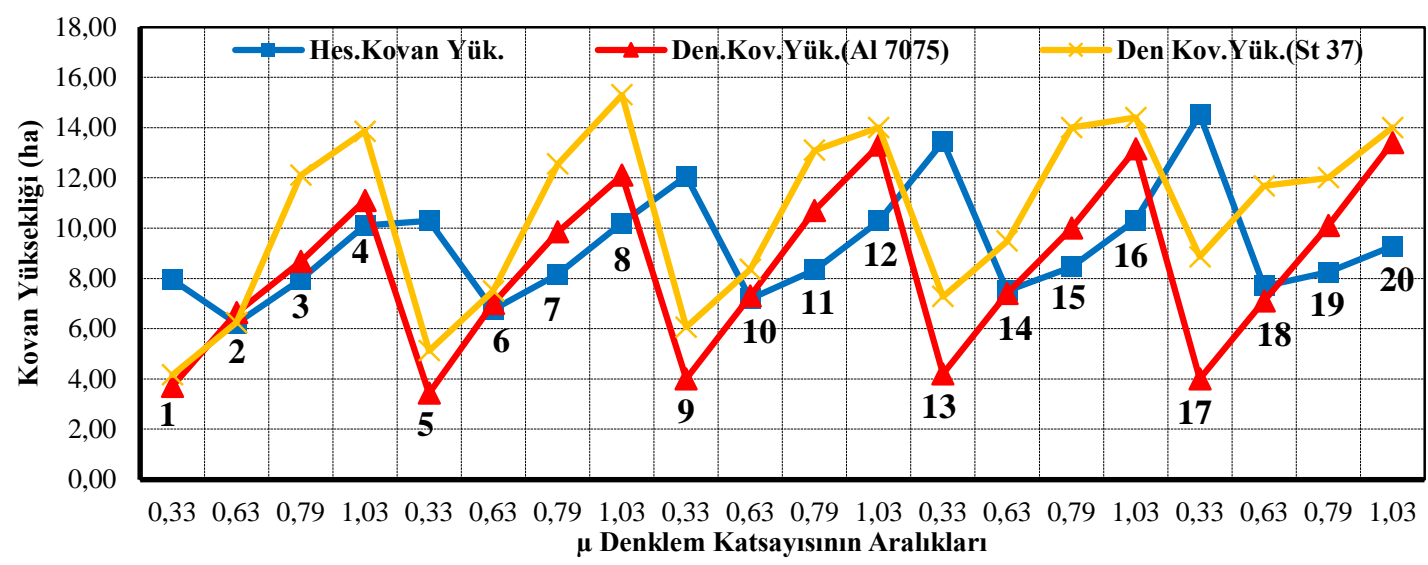

Şekil 10. A7075 ve St37 numunelerinin sürtünmeli delinmesinde delik çapının deneysel ve teorik $\mu$ denklem katsayılarına etkisi.

St37 çelik malzeme A7075-T651 alaşımına göre daha sünek olduğundan ve sünek malzemeler sürtünmeli delme işlemlerinde daha iyi sonuçlar verdiğinden $(\mu)$ denklem katsayısı değerleri daha küçük olmuştur. Ayrıca, değişen malzeme kalınlığı ve delik çapına bağlı olarak meydana gelen değişim de A7075-T651 alaşımına göre daha az olmuştur. St37 çelik levhalarda elde edilen maksimum deneysel ( $\mu$ ) denklem katsayıları ile A7075-T651 alaşımından elde edilene göre yaklaşık olarak \%25 saha büyük olduğu görülmüştür. Ayrıca, St37 levhalarda artan malzeme kalınlığı ile $(\mu)$ denklem katsayısı yaklaşık olarak \%25-30 oranında azalmıştır. Ancak, A7075-T651 alaşımında ise maksimum $(\mu)$ denklem katsayısı değerleri, 2 mm malzeme kalınlığı ve 5 mm delik çapında, 1.21 
olarak kaydedilmiştir. Ayrıca, düzenli olarak artan malzeme kalınlığı ve delik çaplarında, $10 \mathrm{~mm}$ malzeme kalınlığında ve $20 \mathrm{~mm}$ delik çapında, da maksimum ( $\mu$ ) denklem katsayısı 1.21 olarak kaydedilmiştir.

\subsection{2. $\mu$ Katsayısının Al 7075 ve St 37 Malzeme Kalınıklarına Göre Analizi}

Şekil 11'deki grafikte $\mu$ denklem katsayısının A7075 ve St37 malzeme kalınlığına göre etkisi gösterilmiştir. Bu grafikte kovan yüksekliğini belirlemek için gerekli olan denklem katsayısı değerleri malzeme kalınlığına bağlı olarak Z. Demir'in yapmış olduğu çalışmadan elde ettiği ve Şekil 9'da gösterildiği grafiklerden seçilmiştir[16]. Grafikte, malzeme kalınlı̆̆ına bağlı olarak $\mu$ değerleri Şekil 9a'daki grafikten seçilerek kovan yüksekliği hesaplanmıştır. Hesaplanan değerler deneysel kovan yükseklikleri ile karşılaştırılmıştır. Deneysel ölçülen kovan yüksekliği değerleri ile malzeme kalınlığına göre seçilen denklem katsayısına göre hesaplanmış kovan yüksekliği değerlerinin değişim grafikleri benzerlik göstermiştir.

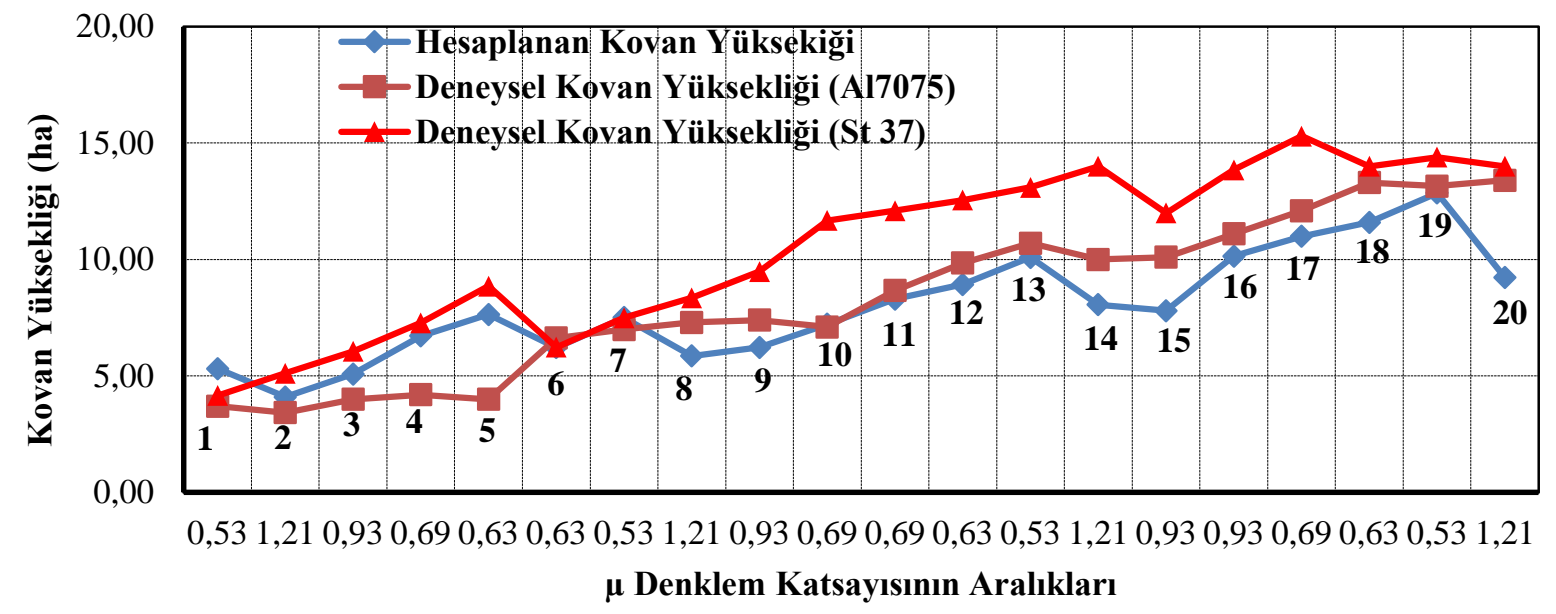

Şekil 11. $\mu$ Denklem Katsayısının A7075 ve St37 Malzeme Kalınlı̆̆ına Göre Etkisi.

\subsection{3. $\mu$ Denklem Katsayısının Kovan Yüksekliğine Göre A7075 ve St37 İçin En Uygun Seçimi}

Kovan yüksekliğini teorik olarak hesaplamak için literatürde yapılan çalışmalarda $\mu$ değerinin seçimi önemli bir parametre olarak karşımıza çıkmaktadır. Bu nedenle literatürde $\mu$ değerinin 0.25 ile 1.21 arasında seçilebileceği belirtilmiştir[16]. Ancak yapılan analizde deneysel kovan yükseklikleri ile hesaplanan kovan yükseklikleri arasında önemli farkların olduğu tespit edilmiştir. Bu nedenle $\mu$ denklem katsayısı değerinin tespit edilmesi ve sınırlarının yeniden belirlenmesi gerekliliği ortaya çıkmıştır. Şekil 12'de St37 çelik malzemesi için $\mu$ denklem katsayısının değerlerinin sınırları, deneysel çalışmadan elde edilmiş kovan yüksekliği değerlerine bağlı olarak yeniden tespit edilmiştir.

Şekil 12'de St37 malzemesinin sürtünmeli delinmesinde delik çaplarına göre $\mu$ değerinin tespiti yapılmıştır. 1-4 sıra numaralı deneylerde $\mathrm{t}=2 \mathrm{~mm}$ kalınlığındaki malzemelerin $\varnothing 5, \varnothing 10, \varnothing 15, \varnothing 20 \mathrm{~mm}$ çaplarında sürtünmeli delinmesinde $\mu$ değerleri 0.75 ile 0.44 aralığında değerler almıştır. Sırasıyla, 5-8 sıra numaralı deneylerde $t=4$ $\mathrm{mm}, 9-12^{\prime}$ 'de $\mathrm{t}=6 \mathrm{~mm}, 13-16$ 'de $\mathrm{t}=8 \mathrm{~mm}$ ve $17-20$ 'de ise $\mathrm{t}=10 \mathrm{~mm}$ kalınlığındaki St37 çelik malzemelerin $\varnothing 5$, $\varnothing 10, \varnothing 15, \varnothing 20 \mathrm{~mm}$ çaplarında sürtünmeli delinmesinde $\mu$ denklem katsayısı değerlerinin yine sırasıyla, $0.75-0.39$, $0.72-0.44,0.62-0.45$ ve 0.53-0.45 aralıklarında değişmiştir. Ayrıca, yapılan analizde hesaplanan kovan yüksekliği ile deneysel kovan yüksekliği arasında büyük benzerlik olduğu görülmüştür. $\mu$ değerinin $6 \mathrm{~mm}$ kalınlıklardaki malzemelerde 0,75 ile 0.37 arasında değiştiği, $8 \mathrm{~mm}$ ve üstü kalınlıklar için ise 0,62 ile 0,35 arasında değiştiği tespit edilmiştir. 


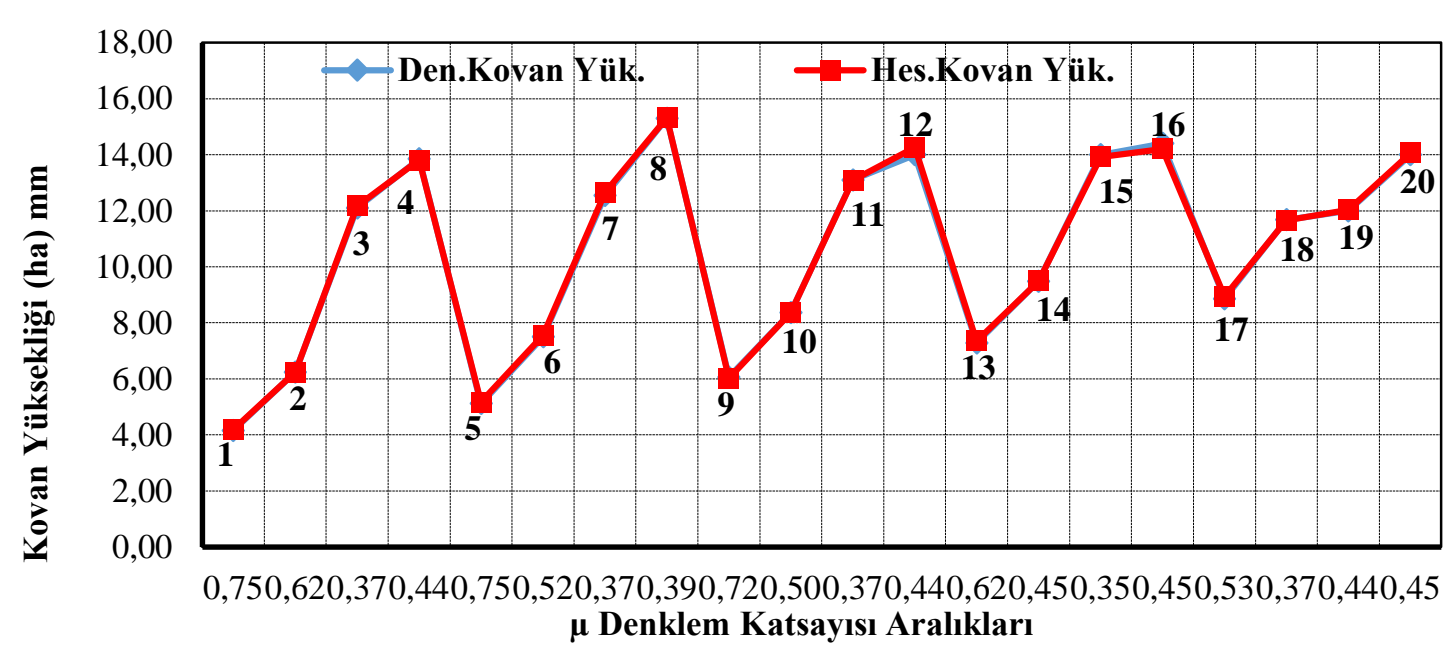

Şekil 12. St37 için kovan yüksekliğine göre en uygun $(\mu)$ değerinin seçilmesi.

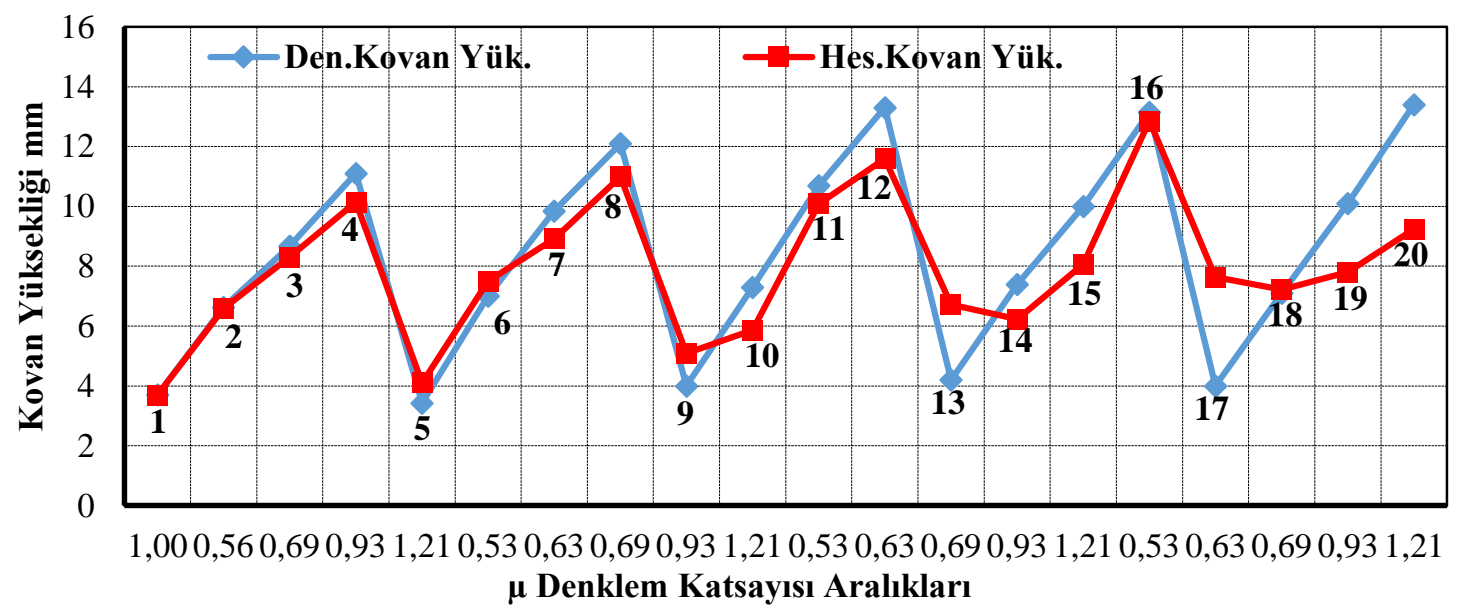

Şekil 13. A7075-T651 için kovan yüksekliğine göre en uygun $(\mu)$ değerleri.

Şekil 13'te Al 7075 alaşımının sürtünmeli delinmesinde delik çaplarına göre $\mu$ değerleri tespiti edilmiştir. 14 sıra numaralı deneylerde $\mathrm{t}=2 \mathrm{~mm}$ kalınlığındaki malzemelerin $Ø 5, \varnothing 10, \varnothing 15, \varnothing 20 \mathrm{~mm}$ çaplarında sürtünmeli delinmesinde $\mu$ değerleri 1 ile 0.56 aralığında değerler almıştır. Sırasıyla, 5-8 sıra numaralı deneylerde $t=4 \mathrm{~mm}$, 9-12'de $\mathrm{t}=6 \mathrm{~mm}, 13-16$ 'de $\mathrm{t}=8 \mathrm{~mm}$ ve $17-20$ 'de ise $\mathrm{t}=10 \mathrm{~mm}$ kalınlığındaki St37 çelik malzemelerin $\varnothing 5$, Ø10, $\varnothing 15, \varnothing 20 \mathrm{~mm}$ çaplarında sürtünmeli delinmesinde $\mu$ denklem katsayısı değerlerinin yine sırasıyla, 1.21-0.53, $0.93-$ $0.53,0.6-0.45$ ve 0.63-1.21 aralıklarında değişmiştir. Ayrıca yapılan analizde hesaplanan kovan yüksekliği ile deneysel kovan yüksekliği arasında $6 \mathrm{~mm}$ kalınlığına kadar büyük oranda benzerlik olduğu görülmüştür. A7075 için $\mu$ denklem katsayısı değerinin sınırları 0.53 ile 1.21 arasında değişmiştir.

\section{Sonuçlar}

A7075 alaşımının HSS ve St37 çelik levhaların ise WC takımlar ile sürtünmeli delinmesinde ölçülen kovan yüksekliği değerlerine bağlı olarak elde edilmiş sonuçlar aşağıda sıralanmıştır.

- Literatürde verilen $(\mu)$ mü denklem katsayısı değerlerinin 0.25 ile 1.21 aralı̆̆ında değerler alacağı belirtilmiştir. Ancak, mevcut deneysel çalışmada, A7075-T651 alaşımının sürtünmeli delinmesinde $(\mu)$ mü denklem katsayısı değerlerinin 0.53 ile 1.21 arasında olduğu tespit edilmiştir. Malzeme kalınlığı arttıkça $\mu$ denklem katsayı değeri azalmışıtır. St37 çelik levhaların sürtünmeli delinmesinde ise $(\mu)$ mü denklem katsayısı değerlerinin 0.39 ile 0.75 arasında olduğu tespit edilmiştir. Malzeme kalınlığı arttıkça $\mu$ denklem katsayının değeri yaklaşık olarak \%40 oranında azalmıştır. 
- St37 çelik levhaların sürtünmeli delinmesinde, A7075-T651 alaşımına göre daha küçük $(\mu)$ denklem katsayıs1 değerleri kaydedilmiştir. Ayrıca, 2mm St37 çelik levha kalınlığında, $5 \mathrm{~mm}$ delik çapında bu değer $0.75,20 \mathrm{~mm}$ delik çapında ise 0.44 olarak kaydedilmiştir. Artan malzeme kalınlığı ile ( $\mu$ ) denklem katsayısının delik çapına bağlı olarak değişim bandı aralığı azalmıştır. Bu aralık $2 \mathrm{~mm}$ malzeme levha kalınlığında yaklaşık olarak \% 50 iken $10 \mathrm{~mm}$ malzeme kalınlığında ise \%20'e azalmıştır.

- A7075-T651 alaşımının sürtünmeli delinmesi işleminde kaydedilen $(\mu)$ denklem katsayısı değerleri St37 çelik levhalara göre, yaklaşık olarak \%25 daha büyük olmuştur. Ayrıca, $(\mu)$ denklem katsayısı, delik çapına ve malzeme kalınlığına bağlı olarak, St37 çelik levhalara göre daha düzensiz bir değişim sergilemiştir. Bu da A7075-T651 alaşımının St37 çelik malzemeye göre oldukça gevrek olmasına atfedilir. Bu düzensiz değişime rağmen artan malzeme kalınlığı ile birlikte artan delik çapı şartlarında $(\mu)$ denklem katsayısı yaklaşık olarak \%20 oranında artış göstermiştir.

- A7075-T651 alaşımında, 2 mm malzeme kalınlığında ve $5 \mathrm{~mm}$ delik çapında ( $\mu$ ) denklem katsayısı 1.21 olarak kaydedilirken $10 \mathrm{~mm}$ malzeme kalınlığında ve $20 \mathrm{~mm}$ delik çapında da en büyü ( $\mu$ ) denklem katsayısı, 1.21 olarak, elde edilmiştir. Böylece, sürtünmeli delinecek levhanın kalınlığına göre uygun delik çapının seçilmesi, uygun sonuçların elde edilmesi açısından oldukça önemlidir.

- St37 çelik levhalar A7075-T651 alaşımına göre daha sünek olduğundan, St37 çelik levhaların sürtünmeli delinmesinde daha büyük kovan yüksekliği değerleri elde edilmiştir.

\section{Kaynaklar}

[1] Brinksmeier E. Prediction of tool fracture in drilling. Ann CIRP 1990; 39:97-100.

[2] Cantero JL, Tard'1o MM, Canteli JA, Marcos M, Migu' elez M H. Dry drilling of Ti - 6Al - 4V alloy. Int J Machine Tools \& Manuf 2005; 45: 1246-1255.

[3] Chow HM, Lee SM, Yang LD. Machining characteristics study of friction drilling on aisi 304 stainless steel. J Mater Process Technol 2008; 207: 180-186.

[4] Lee SM, Chow HM, Huang FY, Yan BH. Friction drilling of austenitic stainless steel by uncoated and PVD AlCrN TiAlN coated tungsten carbide tools. Int J Machine Tools an\& Manuf 2009; 49: $81-88$.

[5] Van Geffen JA. Piercing tools. US Patent 1976; 3.939.683.

[6] Van Geffen JA. methods and apparatuses for forming by frictional heat and pressure holes surrounded each by a boss in a metal plate or the wall of a metal tube. US Patent 1979; 4. 175. 413.

[7] Van Geffen JA. Rotatable piercing tools for forming bossed holes. US Patent 1980; 4.185.486.

[8] Miller SF. Tao J, Shih AJ. Friction drilling of cast metals. Int J Machine Tools \& Manuf 2006; 46: 1526 - 1535.

[9] Gopal Krichna PV, Kishore K, Satyanarayana VV. Some investigations in friction drilling AA6351 using high speed steel tools. ARPN J Engin Appl Sci 2010; 5: 1819-6608.

[10] Miller SF, Blau PJ, Shih AJ. Tool wear in friction drilling. Int Machine Tools \& Manuf 2007; 47: 1636-1645.

[11] Doğru N. AISI 1010 çelik malzemenin sürtünmeli delme yöntemiyle delinmesinde işleme karakteristiklerinin araştırılması. Yüksek Lisans Tezi, Fırat Üniversitesi Fen bilimleri Enstitüsü, Elazı̆̆, 2010

[12] Sara AEB, Hazem EES, Ahmed MEB, Tawfik TEM. Experimental and thermo-mechanical modeling optimization of thermal friction drilling for aisi 304 stainless steel, CIRP J Manuf Sci Technol 2018;20: 84-92

[13] Eliseev AA, Fortuna SV, Kolubaev EA, Kalashnikova TA. Microstructure modification of 2024 aluminum alloy produced by friction. Mater Sci \&Engin A 2017; 691: 121-125

[14] Bilgin MB, Gök K, Gök A. Three-dimensional finite element model of friction drilling process in hot forming processes. Proceed Inst Mech Engin Part E: J Process Mech Engin 2017; 231(3): 548-554, 2017.

[15] Özek C, Demir Z. A7075-T651 alaşımının sürtünmeli delinmesinde kovan yüksekliğinin malzeme kalınlığına göre araştırılması. Dicle Ün Müh Fak Müh Der 2013; 4(2): 61-67.

[16] Demir Z. A geometrical approach to deriving a bushing height equation for thermal friction drilling. Mater in Technol 2019; 53 (2): 215-224 